\title{
TECHNOLOGICAL PECULIARITIES OF WELDING OF WROUGHT MAGNESIUM ALLOYS BY ELECTRON BEAM IN VACUUM
}

\author{
A.A. BONDAREV and V.M. NESTERENKOV \\ E.O. Paton Electric Welding Institute, NASU \\ 11 Bozhenko Str., 03680, Kiev, Ukraine. E-mail: office@paton.kiev.ua
}

\begin{abstract}
Magnesium alloys find ever wider application in different fields of industrial production, especially when products should have the lowest mass characteristics. Use of magnesium alloys for manufacture of such structures is the most challenging, but in this case, the technologies of their manufacture including also processes of welding using different methods, should be available and reliable. At the present time many specialists attribute the EBW to the category of high technologies. Firstly, the EBW process is carried out under the conditions of vacuum environment, which absolutely eliminates any oxidizing processes of liquid metal in weld pool. Moreover, during melting in vacuum the refining purification of molten metal from harmful impurities takes place, and strength characteristics of joints are the highest in this case. In the present work the results of experimental investigations of weldability of wrought magnesium alloys of different thicknesses produced using electron beam are given. The influence of the system of alloying and parameters of mode on formation of welds and sizes of penetration zone of billets of different thickness was shown. The strength characteristics of welded butt joints were determined. 8 Ref., 4 Tables, 6 Figures.
\end{abstract}

$\boldsymbol{K} \boldsymbol{e} \boldsymbol{y} \boldsymbol{w} \boldsymbol{O} \boldsymbol{r} \boldsymbol{s}:$ electron beam welding, magnesium al loys, welding modes, strength of welded joints, microstructure of weld and base metal

Magnesium alloys, being the lightest structural material and having comparatively high mechanical properties, are characterized by high chemical resistance towards a number of aggressive environments and are capable to perceive high impact loads due to low elasticity modulus, and also well treated by a cutting tool. The number of grades of industrial wrought magnesium alloys approaches to about two dozens. Among light metals aluminium is 1.5 times and titanium 2.5 times heavier than magnesium, and steel is 4 times heavier than the latter. This explains growing interest to application of magnesium alloys in different fields of industry both in our country as well as abroad [1-4].

The application of magnesium alloys as a structural material in welded structures would not be possible without development of methods of their technological treatment and welding [5, 6].

The large number of works [7] is devoted to the weldability of magnesium alloys of different systems of alloying using arc welding methods, including also superlight structural alloys of the $\mathrm{Mg}-\mathrm{Li}$ system.

However, as the analysis of works devoted to investigations of weldability of magnesium alloys showed, these matters are still not sufficiently

(C) A.A. BONDAREV and V.M. NESTERENKOV, 2014 highlighted in the literature. And the information on weldability of magnesium alloys using electron beam is practically absent.

The results of earlier carried out investigations evidence that magnesium alloys of grades MA2-1, MA12, IMV2, IMV2-1 and alloys of the alloying systems $\mathrm{Mg}-\mathrm{Zn}-\mathrm{Zr}-\mathrm{Ce}$ and $\mathrm{Mg}-\mathrm{Nd}-\mathrm{Zr}$ can be successfully welded using arc methods. The strength factor of joints for most of them is in the range of $0.9-1.0$ of the base metal. Other strength values of joints are also at the level of properties of base metal at a high density of weld metal.

The main problem in welding of magnesium alloys is to prevent formation of hot cracks in welded joints.

At the E.O. Paton Electric Welding Institute the investigations on weldability of magnesium alloys, the grade and chemical composition of which are given in Table 1, were carried out.

MA2-1 alloy belongs to lower-alloy mediumstrength magnesium alloys. It has a good ductility in hot state and is good welded using arc methods. It was used in work to select parameters of mode for welding billets of this alloy of up to $200 \mathrm{~mm}$ thickness.

The alloy VMD-3 based on the $\mathrm{Mg}-\mathrm{Zn}-\mathrm{Zr}$ system belongs to the category of high-alloy and the most strength magnesium wrought alloys. This alloy is additionally alloyed with cadmium and lanthanum. It is known that lanthanum during its introduction in the amount of $0.2-0.8 \%$ 
Table 1. Chemical composition of magnesium alloys investigated, wt.\%

\begin{tabular}{|c|c|c|c|c|c|c|c|c|c|c|c|c||}
\hline Alloy & $\mathrm{Al}$ & $\mathrm{Zn}$ & $\mathrm{Mn}$ & $\mathrm{Li}$ & $\mathrm{Cd}$ & $\mathrm{Nd}$ & $\mathrm{La}$ & $\mathrm{Zr}$ & $\mathrm{Ni}$ & $\mathrm{Si}$ & $\mathrm{Fe}$ & $\mathrm{Be}$ \\
\hline MA2-1 & $3.8-5.0$ & $0.8-1.5$ & $0.4-0.8$ & - & - & - & - & - & 0.005 & 0.10 & 0.05 & 0.02 \\
\hline VMD-3 & - & $2.3-3.5$ & - & - & $1-2$ & - & $0.5-1.0$ & $0.5-0.9$ & 0.005 & 0.15 & 0.03 & 0.02 \\
\hline VMD-6 & 0.1 & $5.5-7.0$ & - & - & $0.2-1.0$ & $1.4-2.0$ & - & $0.5-0.9$ & 0.004 & 0.15 & 0.04 & 0.002 \\
\hline IMV-2 & 5.0 & 1.0 & 0.4 & 8.0 & 4.0 & - & - & - & - & - & - \\
\hline
\end{tabular}

Table 2. Mechanical properties of investigated magnesium alloys

\begin{tabular}{|c|c|c|c|c|c||}
\hline \hline Alloy & Semi-product & $\sigma_{\mathrm{t}}, \mathrm{MPa}$ & $\sigma_{0.2}, \mathrm{MPa}$ & $\delta, \%$ & \multicolumn{1}{c|}{$\mathrm{J} / \mathrm{cm}^{2}$} \\
\hline MA2-1 & Plate & $270.3-280.0$ & $210.6-230.5$ & $0.5-0.7$ \\
\hline VMD-3 & Sheet & $270.1-280.3$ & 230.5 & $6.5-9.5$ \\
\hline VMD-3 & Plate & 320 & 260 & 13.2 \\
\hline VMD-6 & Sheet & $200.4-210.2$ & $90.2-90.5$ & $5.3-8.7$ \\
\hline IMV-2 & Same & $220-230$ & $190.0-190.5$ & 0.25 \\
\hline
\end{tabular}

provides intensified refining of grains and increases strength of alloys of the $\mathrm{Mg}-\mathrm{Zn}$ system. This alloy has a good ductility in hot state and satisfactory weldability. In the work the specimens of this alloy in the form of sheets 2.5 and $10 \mathrm{~mm}$ thick were used.

The alloy VMD-6 is a new high-strength wrought magnesium alloy. It is not weldable and applied for high-load parts. In the work the specimens of this alloy in the form of discs of $6 \mathrm{~mm}$ thickness, cut out of a rod of $160 \mathrm{~mm}$ diameter, were used.

The alloy IMV-2 belongs to the series of superlight structural alloys based on $\mathrm{Mg}-\mathrm{Li}$, it has a low density $\left(1.6 \mathrm{~g} / \mathrm{cm}^{3}\right)$, high specific rigidity and good arc weldability. Besides, the alloys of the system $\mathrm{Mg}-\mathrm{Li}$ have high resistance to hot cracks formation in welding and low sensitivity to hydrogen porosity. However, the presence of high content of lithium with high sensitivity to oxygen in the alloy requires careful protection of molten metal of weld pool and heated adjacent areas of base metal from the surrounding air. For this purpose, it is recommended to apply the argon blowing on the side of penetration in arc welding.

During optimizing the EBW modes and techniques of above-mentioned magnesium alloys the specimens of $12 \mathrm{~mm}$ thickness were used. The properties of investigated alloys are given in $\mathrm{Ta}-$ ble 2 .

In the process of carrying out of investigations all the given grades of alloys were welded without fillers. The assembly of specimens for welding was performed with the smallest possible gaps. Preparation of edges was performed using scraping to the depth of up to $0.1 \mathrm{~mm}$. Before this the specimens were subjected to degreasing with organic solvents.

Welding of billets of alloys MA2-1 and VMD3 of $100 \mathrm{~mm}$ thickness and larger, and $450 \mathrm{~mm}$ length was performed using power source ELA$60 / 60$ with accelerating voltage of $60 \mathrm{kV}$ and beam current of up to $1 \mathrm{~A}$.

The modes of welding of magnesium alloy joints, providing full penetration depth at minimum required power, are given in Table 3.

EBW of mentioned alloys was performed both by static beam as well as by the beam rotating around the circumference. Frequency of oscillations was accepted equal to $300 \mathrm{~Hz}$, and amplitude - to $1.5 \mathrm{~mm}$.

The properties of joints were determined on the round specimens of the type II according to GOST 6996-66, impact toughness was determined on the specimens with Mesnager notch.

Table 3. Condition parameters of welding the magnesium alloys of different thickness $\left(U_{\text {acc }}=60 \mathrm{kV}\right)$

\begin{tabular}{|c|c|c|c||}
\hline Alloy & Thickness, mm & $\begin{array}{c}\text { Beam current, } \\
\mathrm{mA}\end{array}$ & $\begin{array}{c}\text { Welding speed, } \\
\mathrm{m} / \mathrm{h}\end{array}$ \\
\hline MA2-1 & 20 & 80 & 45 \\
\hline MA2-1 & 135 & 430 & 15 \\
\hline MA2-1 & 165 & 430 & 10.5 \\
\hline VMD-3 & 10 & 45 & 55 \\
\hline VMD-3 & 7 & 30 & 24 \\
\hline VMD-3 & 11 & 40 & 24 \\
\hline VMD-3 & 135 & 450 & 14 \\
\hline VMD-6 & 7.5 & 40 & 48 \\
\hline VMD-6 & 7.5 & 30 & 33 \\
\hline IMV-2 & 10 & 22 & 24 \\
\hline IMV-2 & 12 & 27 & 24 \\
\hline
\end{tabular}




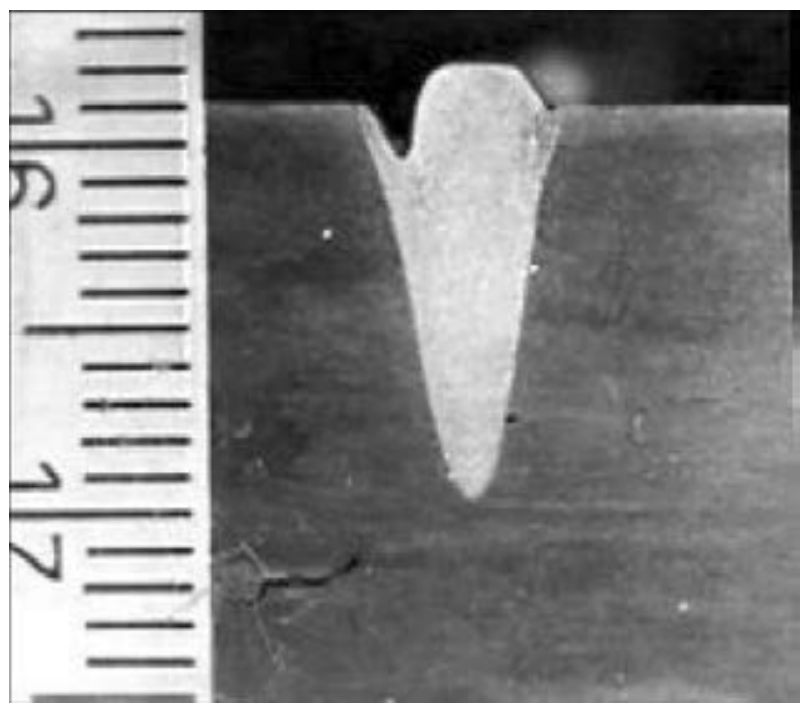

Figure 1. Macrosection of alloy MA2-1 joint with partial penetration

Visual control of the process of EBW of magnesium alloys allowed establishing the fact that depending on the system of alloying the behavior of molten metal of weld pool is different. Thus, in welding of alloys MA2-1 and VMD-3 with full penetration and alloy IMV-2 with full and partial penetration the process runs smoothly, without splashes and spattering of molten metal. In this case in welds the defects of the type of undercuts of 2-3 mm depth on the both sides of upper bead along the fusion zone are observed ( $\mathrm{Fi}$ gure 1).

In EBW one more feature in formation of a joint was observed, which is peculiar only to magnesium alloys. It consists in the fact that in welding with full penetration almost in all the cases on the side of root weld the blowing out of molten metal occurs by pressure of vapors in the crater. As a result the undercut of up to $3.5 \mathrm{~mm}$

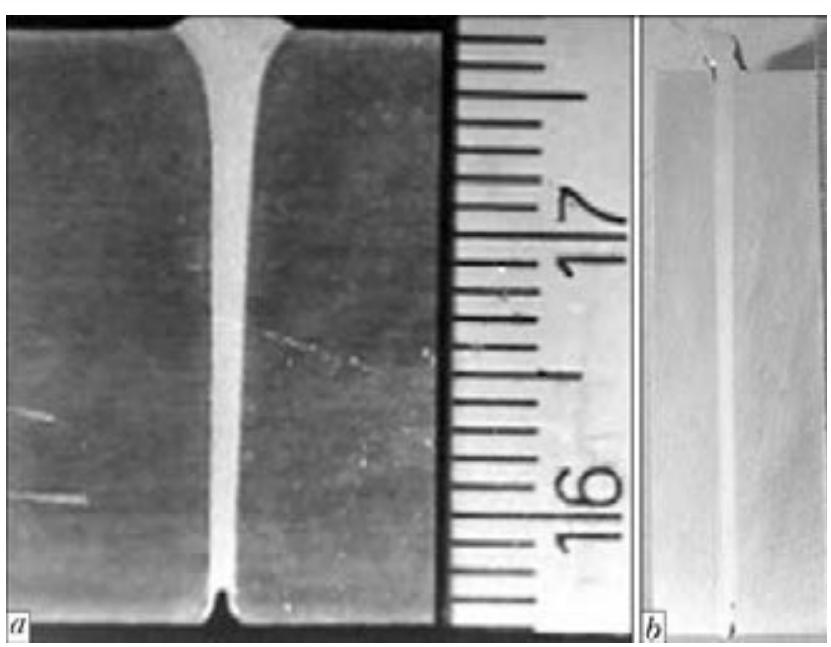

Figure 2. Formation of root part of weld $20(a)$ and 100 (b) $\mathrm{mm}$ depth in EBW of MA2-1 alloy with full penetration

depth is formed (Figure 2). With the growth of thicknesses of billets being welded the deep undercuts are formed both on the side of weld root as well as on the side of upper bead (Figure 2, a). To remove these defects the upper and lower backing straps are applied, which are removed after welding (Figure 3).

In the process of carrying out the investigations all the welded joints of magnesium alloys were subjected to X-ray control to detect inner defects. The results of analysis showed that in EBW the pores and cracks are not formed. Cracks were not detected even on the billets of alloy VMD-6, which by their design correspond to one of the most complicated variants of round sample for determination of tendency to cracks formation. The results of investigations of properties of joints of magnesium alloys are given in Table 4 . The joints of all the given alloys were not subjected to heat treatment after welding.

Table 4. Mechanical properties of welded joints of magnesium alloys

\begin{tabular}{|c|c|c|c|c|c||}
\hline \hline Alloy & $\begin{array}{c}\text { Thickness of metal to } \\
\text { be welded, } \mathrm{mm}\end{array}$ & $\sigma_{\mathrm{t}}, \mathrm{MPa}$ & $\sigma_{0.2}, \mathrm{MPa}$ & $\delta, \%$ & $K C V, \mathrm{~J} / \mathrm{cm}^{2}$ \\
\hline MA2-1 & 20 & $\frac{250.1-250.7}{250.4}$ & $\frac{210.2-250.3}{230.6}$ & $\frac{8.0-12.5}{10.4}$ & 0.5 \\
\hline MA2-1 & 135 & $\frac{250.8-270.6}{260.9}$ & $\frac{120.2-130.4}{120.8}$ & $\frac{11.7-16.7}{15.2}$ & $\frac{0.75-1.0}{0.85}$ \\
\hline VMD-3 & 10 & $\frac{250.6-270.9}{260.8}$ & $\frac{220.5-230.4}{220.7}$ & $\frac{5.2-8.4}{7.5}$ & 0.4 \\
\hline VMD-3 & 135 & $\frac{220.3-250.9}{240.5}$ & $\frac{220.0-240.8}{230.2}$ & 6.7 & 0.5 \\
\hline VMD-3 & 135 & $\frac{260.3-270.2}{260.85}$ & $\frac{250.2-260.3}{250.6}$ & 5.4 & 0.5 \\
\hline IMV-2 & 12 & $\frac{200.5-220.4}{210.8}$ & $\frac{170.8-180.1}{10.8}$ & 4.0 & $0.3-0.7$ \\
\hline VMD-6 & 7.5 & $\frac{200.6-200.8}{200.6}$ & $\begin{array}{c}\text { Fracture beyond the } \\
\text { base }\end{array}$ & - & 0.4 \\
\hline
\end{tabular}


Analysis of results of mechanical properties of fractured specimens showed that in the alloys IMV-2 and VMD-6 the fracture occurred in all the cases on base metal at the distance of 10$15 \mathrm{~mm}$ from the weld axis. The difference in values of ultimate strength for IMV-2 sheets 10 and $12 \mathrm{~mm}$ thick was not detected. Fracture of specimens of alloys MA2 and VMD-3 occurred mostly along the weld metal. In EBW of MA2-1 alloy of $135 \mathrm{~mm}$ thickness and next cutting out of specimens of different areas of welds in depth the anisotropy of strength characteristics in weld was not detected.

Impact toughness of joints (weld metal and HAZ) for investigated grades of alloys is at the level of similar characteristics for base metal.

Strength factor of joints for alloys IMV-2 and VMD-6 is practically equal to one. For the alloys MA2-1 and VMD-3 it is in the range of $0.95-1$, and for VMD-3 is $0.75-0.85$.

Analysis of microstructure of different areas of joints of magnesium alloys showed that structure of weld metal in EBW almost does not differ from that of alloys in cast state. Considering the high rates of solidification in EBW somewhat smaller size of grains and thickness of intergranular sublayers are observed as compared to the structure of welds in arc welding methods [8]. Visual defects in weld metal on the alloys MA2-1, VMD-6 and IMV-2 are not observed (Figure 4).

In HAZ metal at the area adjacent to the fusion zone, recrystallziaiton of initial structure of base metal with formation of equiaxial grains is observed. However, here the general direction of

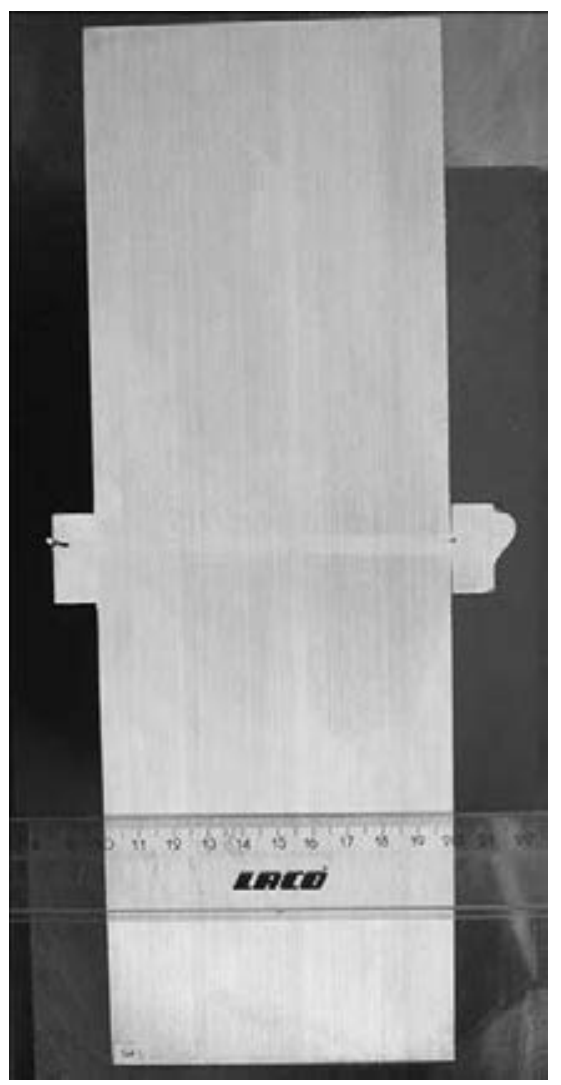

Figure 3. Formation of welds in EBW of alloy MA2-1 with two backing straps

texture of base metal is observed (Figure 5). Thickening of intergranular sublayers with precipitation of low-melting eutectics in HAZ metal is about 3-5 times higher than in base metal.

Figure 6 presents for comparison structure of base metal of alloys MA2-1, VMD-6 and IMV-2.

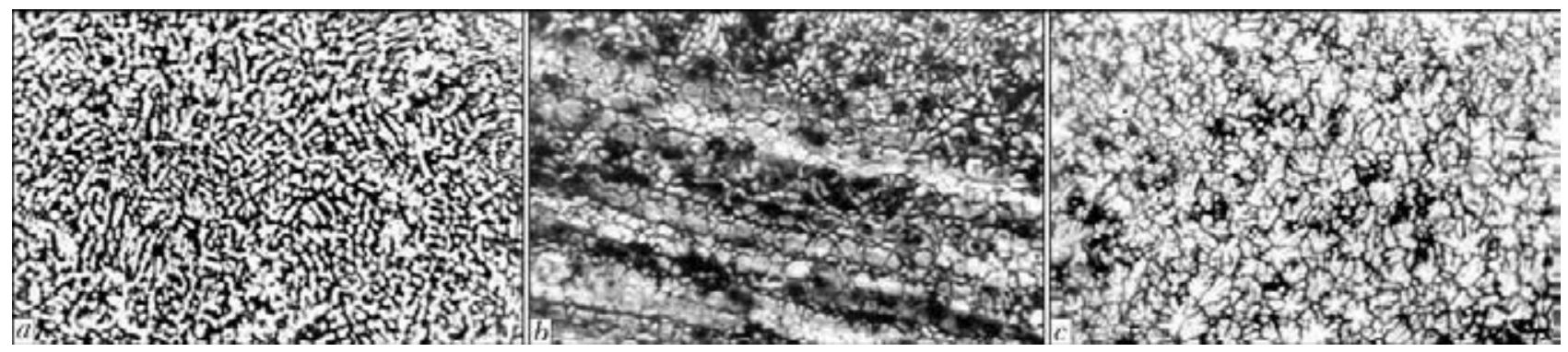

Figure 4. Microstructure $(\times 150)$ of weld metal on alloys MA2-1 $(a)$, VMD-6 $(b)$ and IMV-2 (c)

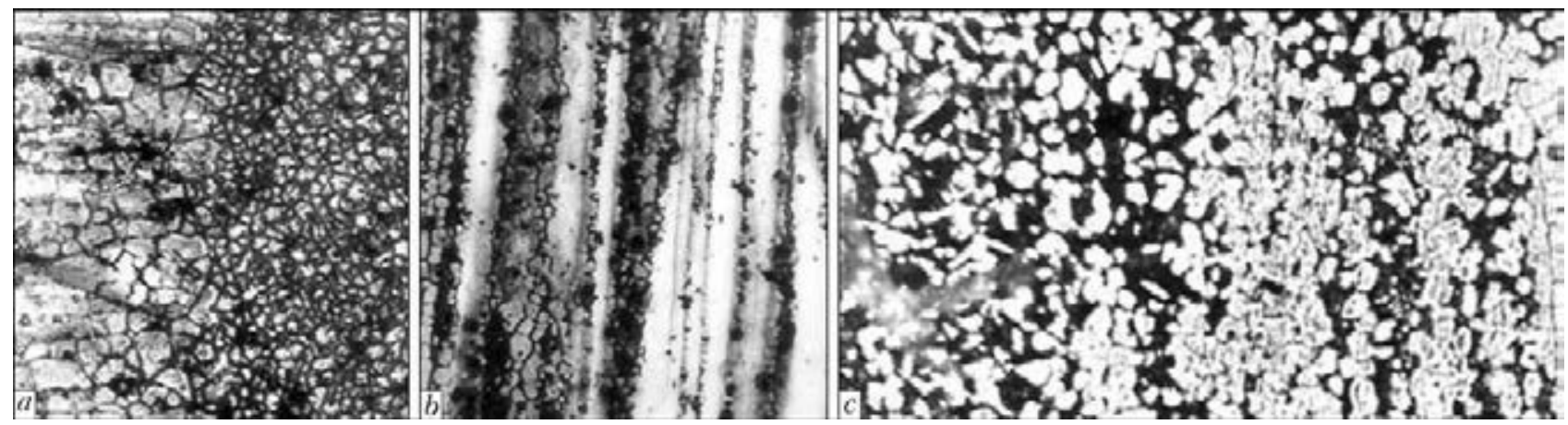

Figure 5. Microstructure $(\times 150)$ of welded joints of alloys MA2-1 $(a)$, VMD-6 $(b)$ and IMV-2 $(c)$ in the fusion zone 


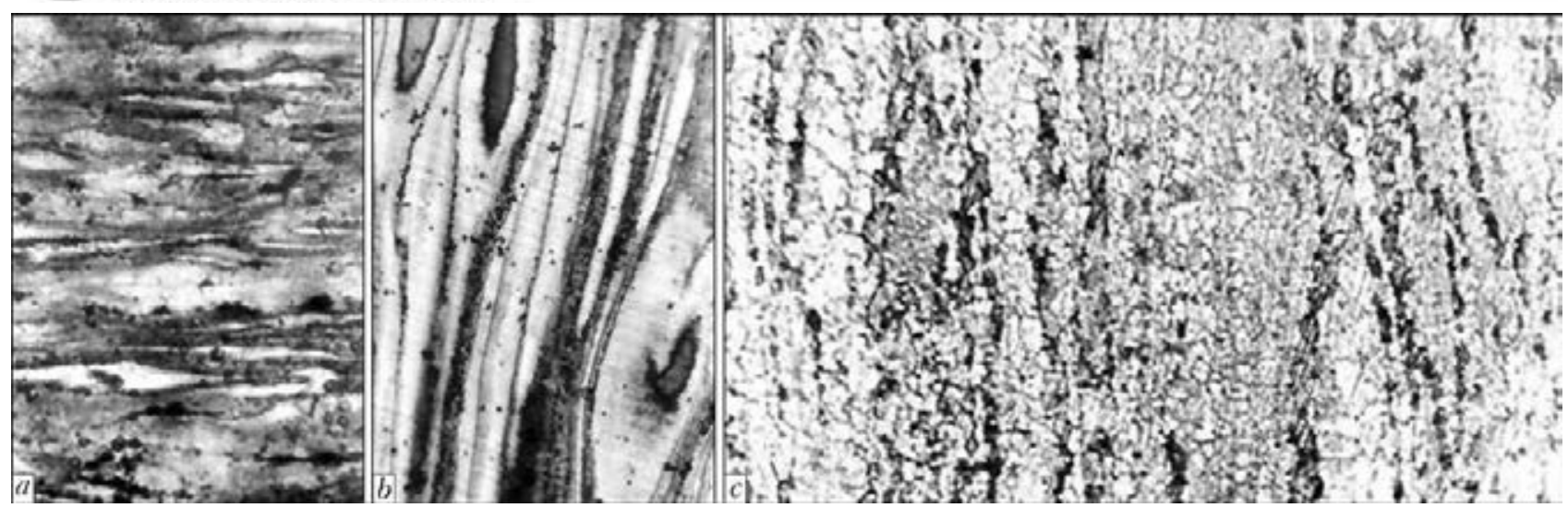

Figure 6. Microstructure $(\times 150)$ of base metal of alloys MA2-1 (a), VMD-6 (b) and IMV-2 (c)

\section{Conclusions}

1. Complex investigations of weldability of magnesium alloys, using electron beam in vacuum, including high-strength $\mathrm{Mg}-\mathrm{Li}$ alloys were carried out.

2 . It was established that to provide high quality of formation and strength properties of joints, welding should be performed using scanning electron beam at the frequencies $200-700 \mathrm{~Hz}$ and amplitude of $1.5-2.5 \mathrm{~mm}$.

3. It was shown that strength characteristics of welded joints of high-strength magnesium alloys are at the level not lower than $95 \%$ of similar properties of base metal.

4. It is recommended to use cover plates and backings under the butt of the same metal at the thickness of not less than 5-10 $\mathrm{mm}$ in preparation of butt joints to prevent formation of defects in the form of lowering of surface of welds or flowing out of molten metal on the back side of weld.
1. (1978) Magnesium alloys: Refer. Book. Vol. 1: Metals science of magnesium and its alloys. Ed. by M.B. Altman, A.F. Belov, V.I. Dobatkin et al.; Vol. 2: Technology of production and properties of castings and strained semi-products. Ed. by I.I. Guriev, M.V. Chukhrov. Moscow: Metallurgiya.

2. Rokhlin, L.L., Nikitina, N.I., Volchenkova, V.A. (2006) Examination of magnesium-enriched alloys $\mathrm{Mg}-\mathrm{Al}_{2} \mathrm{Cu}$. Metally, 2, 104-108.

3. Drits, M.E. (1964) Magnesium alloys for service at higher temperatures. Moscow: Nauka.

4. Vozdvizhensky, V.M., Grachev, V.A., Skassky, V.V. (1984) Cast alloys and technology of their melting in machine-building. Moscow: Mashinostroenie.

5. (1978) To problem of electron beam welding of magnesium alloys. In: Magnesium alloys. Moscow: Nauka.

6. Ejdenzon, M.A. (1974) Metallurgy of magnesium and other light metals. Moscow: Metallurgiya.

7. (1978) Magnesium alloys: Transact. of A.A. Baikov Institute of Metallurgy. Moscow: Nauka.

8. Bondarev, A.A., Nesterenkov, V.M. (2013) Study of weldability of magnesium alloy MA2 by electron beam in vacuum. Kompres. Energetich. Mashinostroenie, 2, 21-28.

Received 10.07.2013 